\title{
Effect of 6-BAP and Sucrose Pulsing on Vase Life of Lotus (Nelumbo nucifera)
}

\author{
K.B.B. Chathuri and K.H. Sarananda ${ }^{1 *}$ \\ Postgraduate Institute of Agriculture \\ University of Peradeniya \\ Sri Lanka
}

\begin{abstract}
Lotus (Nelumbo nucifera) belonging to the family Nelumbonaceae has high demand, especially for religious purposes and floral decorations. Lotus is widely distributed in tanks in the dry zone of Sri Lanka. After harvesting, flowers are transported to various destinations. Lotus flowers have a short postharvest life because of senescence, wilting and petal falling. Improper handling, stress during transport, high respiration and transpiration rates could be the main reasons for the short postharvest life of lotus. Therefore, this study was mainly carried out to identify a mode of treatment to extend the vase life of lotus. To study the effect of 6-benzylaminopurine (6-BAP) and sucrose on keeping quality of lotus flowers, four levels of 6-BAP $(0,10,15$ and $20 \mathrm{ppm})$ and four levels of sucrose $(0,2,4$, and $8 \%)$ were tested at ambient temperature. The medium was acidified using 192 ppm citric acid in all treatments while deionized water was used as the control. To study the effect of pulsing, 2\% sucrose solution was used to treat flowers for $0,1,2$ and $4 h$ at ambient temperature. Pulsed flowers were placed in 15 ppm 6-BAP solution. Flower quality was evaluated daily based on percent weight loss, wilting, browning, fading, petal falling and flower opening indices. Parametric data were analyzed using ANOVA while non-parametric data were analyzed using Kruskal-Wallis test. Results revealed that $15 \mathrm{ppm}$ 6-BAP alone was effective in maintaining flower quality. Pulsing with $2 \%$ sucrose solution for 4 h further enhanced the flower quality up to 5 days when they were placed in 15 ppm 6-BAP after pulsing.
\end{abstract}

Key words: 6-Benzylaminopurine (6-BAP), Lotus, Nelumbo nucifera, Pulsing, Senescence.

\section{INTRODUCTION}

Lotus, Nelumbo nucifera, Gaertn, is one of the most beautiful and striking water plants with high cultural and economical value. Lotus has high demand as a cut flower especially for religious purposes, floral decorations and bouquet preparations in Sri Lanka. As Lotus is widely distributed in tanks in the dry zone, transportation to various destination within the country is essential . However, most of the time flowers end up with a short post-harvest life because of early senescence, wilting and petal falling. Therefore, the broad objective of this study was to identify a mode of treatment to extend the vase life of lotus, while the specific objectives of this study were to identify the effect of 6-benzylaminopurine (6-BAP) and sucrose on vase life of lotus and to study the effect of pulsing with $2 \%$ sucrose for different time durations on vase life of lotus.

\footnotetext{
To whom correspondence should be addressed: saranandahewage@yahoo.com Food Research Unit, Department of Agriculture, Gannoruwa, Peradeniya, Sri Lanka
} 


\section{MATERIALS AND METHODS}

The research was conducted at the Department of Crop Science, Faculty of Agriculture, University of Peradeniya. A preliminary study was conducted to establish non-parametric indices (wilting index, browning index, fading index, petal falling index and flower opening index) by observing natural behaviour of cut lotus flowers dipped in de-ionized water. The research was carried out in two steps. The results of the preceding steps were used to plan the subsequent steps.

\section{Plant material}

Cut flowers of $N$. nucifera were obtained from Dambulla area. Flowers were harvested in the evening of previous day and brought in bundles (using dry-pack system) by bus to Kandy during early morning and then carefully transported to the laboratory.

\section{Experimental design}

First experiment was designed as a two factor factorial experiment using Completely Randomized Design (CRD) with twenty replicates, and the second experiment was designed as a Completely Randomized Design (CRD) with four treatments and thirty replicates.

\section{Treatment combinations}

In the first experiment, the effect of 6-BAP and sucrose on vase life of lotus was tested as a two factor factorial experiment. Four levels of 6-BAP $(0,10,15$ and $20 \mathrm{ppm})$ and four levels of sucrose $(0,2,4$, and $8 \%)$ were tested at ambient temperature $\left(26 \pm 2{ }^{\circ} \mathrm{C}\right)$. These levels were decided based on the past studies. De-ionized water was used as the control. In the second experiment, flowers were pulsed with $2 \%$ sucrose for 0 hour, $1 \mathrm{~h}, 2 \mathrm{~h}$ and $4 \mathrm{~h}$ respectively.

\section{Procedure}

In the first experiment, containers of the same size were selected and disinfected by washing with the detergent Teepol ${ }^{\circledR}$. Each of the test solution was prepared according to the relevant concentrations using deionized water. 6-BAP was dissolved using few drops of $1 \mathrm{~N}$ sodium hydroxide $(\mathrm{NaOH})$ and volumerized. The medium was acidified to reduce microbial contaminations using 192 ppm citric acid (Patil and Reddy, 2001) in all treatments including control. Then healthy flowers of same size were selected and randomly divided in to 16 equal groups. The flower stalks were re-cut in water to have equal stalk lengths of $20 \mathrm{~cm}$. Flowers were labeled and initial weights of the flowers were recorded within 3-5 seconds and immediately transferred to the containers filled with $250 \mathrm{ml}$ of the prepared solution.

Based on the results of the first experiment, $15 \mathrm{ppm}$ 6-BAP concentration was selected as the holding solution. Two percent sucrose solution and $15 \mathrm{ppm} 6$-BAP solution were prepared following the same procedure as above. The lowest sucrose concentration (2\%) in the first experiment was used. Then healthy flowers of same size were selected and randomly divided in to four equal groups. After re-cutting the stems, labeling, and weighing, the flowers were dipped in $2 \%$ sucrose solution for 0 hour, $1 \mathrm{~h}, 2 \mathrm{~h}$ and $4 \mathrm{~h}$. At the end of each relevant time period flowers were immediately transferred to the containers filled with $250 \mathrm{ml}$ of $15 \mathrm{ppm}$ 6-BAP solution acidified with $192 \mathrm{ppm}$ citric acid. In both experiments flowers were kept under ambient condition. 
In the first experiment percentage weight loss and visual observations as wilting index, browning index, fading index, petal falling index and extent of flower opening (Table 1), were daily recorded up to the stage where the flowers loose the salable quality. Based on results of the experiment one, flowers treated with $15 \mathrm{ppm}$ 6-BAP showed no flower opening. Therefore, in the second experiment, all other indices were daily recorded except extent of flower opening.

Table 1. Developed scales for visual observations of cut lotus

\begin{tabular}{|c|c|c|}
\hline Indices & Description & Score \\
\hline \multirow[t]{5}{*}{ Browning index } & Complete browning of second whorl & 5 \\
\hline & Browning extended to second whorl & 4 \\
\hline & Complete browning of first whorl & 3 \\
\hline & Browning started at first whorl & 2 \\
\hline & All whorls are fresh & 1 \\
\hline \multirow[t]{5}{*}{ Fading index } & Complete fading of second whorl & 5 \\
\hline & Fading extended to second whorl & 4 \\
\hline & Complete fading of first whorl & 3 \\
\hline & Fading started at first whorl & 2 \\
\hline & All whorls are fresh & 1 \\
\hline \multirow{5}{*}{ Petal falling index } & Complete fall of second whorl & 5 \\
\hline & Petal fall extended to second whorl & 4 \\
\hline & Complete fall of petals at first whorl & 3 \\
\hline & Petal fall started at first whorl & 2 \\
\hline & No petal fall observed & 1 \\
\hline \multirow[t]{5}{*}{ Wilting index } & Complete wilting of second whorl & 5 \\
\hline & Wilting extended to second whorl & 4 \\
\hline & Complete wilting of first whorl & 3 \\
\hline & Wilting started at first whorl & 2 \\
\hline & All whorls are fresh & 1 \\
\hline \multirow[t]{5}{*}{ Extent of flower opening* } & Completely open & 5 \\
\hline & $3 / 4$ opening & 4 \\
\hline & $1 / 2$ opening & 3 \\
\hline & $1 / 4$ opening & 2 \\
\hline & Completely closed & 1 \\
\hline
\end{tabular}

*Based on the preliminary studies, completely closed flowers were considered 'good'.

\section{Statistical analysis}

The parametric data ( $\%$ weight loss) was analyzed by ANOVA while non parametric data (wilting index, browning index, fading index, petal falling index and extent of flower opening) were analyzed by Kruskal Wallis test using MINITAB 15.0 Statistical Package.

\section{RESULTS AND DISCUSSION}

In experiment one, statistical analysis of the data revealed that within each measured visual parameter (wilting index, browning index, fading index and extent of flower opening) all treatments were significantly different $(\mathrm{p}<0.05)$ except the petal falling index in the third day 
of storage. Regarding the percentage weight loss, the treatment effect was non-significant $(p>0.05)$ for factor one (four levels of 6-BAP) whereas treatment effect was significant $(p<0.05)$ for factor two (four levels of sucrose). There was a significant interaction effect between 6-BAP and sucrose levels $(\mathrm{p}<0.05)$. Wilting index as affected by 6-BAP and sucrose in the third day of storage is shown in Fig. 1.

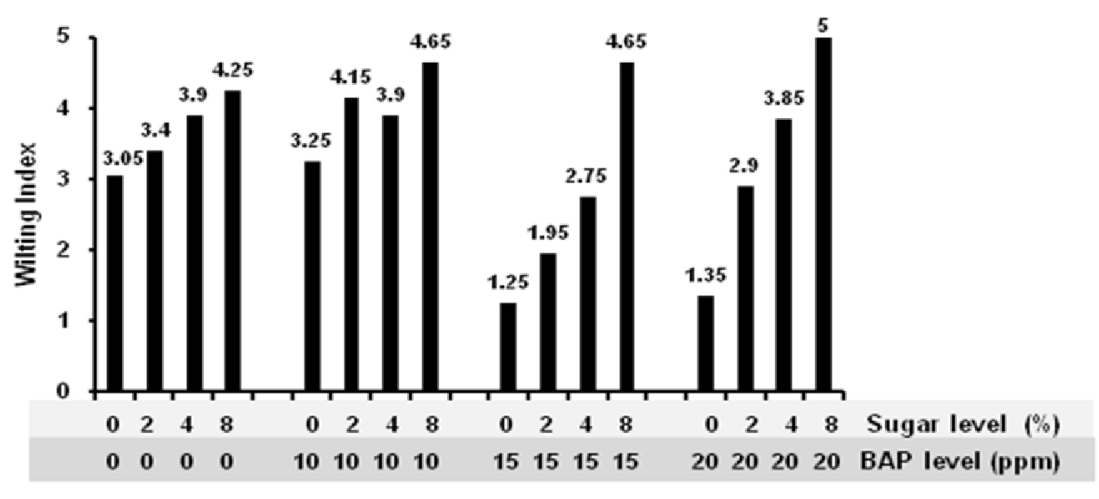

Treatment Combinations

Fig. 1. Wilting index as affected by 6-BAP and sucrose in the $3^{\text {rd }}$ day of storage

In the third day of storage, lowest wilting was observed in flowers treated with 15 ppm 6BAP without sucrose. Wilting was highest in flowers treated with 20 ppm 6-BAP with $8 \%$ sucrose. At each 6-BAP level, wilting was accelerated with gradual increase in sucrose concentration (Fig. 1). Relatively higher flower opening followed by wilting was observed in flowers treated with $10 \mathrm{ppm} 6$-BAP with $8 \%$ sucrose and $20 \mathrm{ppm} 6$-BAP with $8 \%$ sucrose.

A precise sucrose concentration is required for a particular cultivar on the basis of certain plant characteristics. At 9\% sucrose, withering was markedly enhanced in fresh flowers of Lupinus hartwegii (Mohan, 1977). Faster break down of sugar coupled with rapid loss of water through transpiration caused quick senescence of flower cells or in the attached branch with flower. Therefore, cut flowers could be provided with the supplemental dose of sucrose maintaining the post harvest life. However, either excessive or lower doses of sucrose equally influenced the vase life adversely that could be attributed to the unbalancing of sugar-water concentration in the cellular tissues of cut roses (Butt, 2005). Although the provision of energy is a necessary condition for the survival of petals, it is not sufficient to explain senescence. At the stage of maximal withering, the petals are still rich in hexoses. It is not a lack of substrate which induces the onset of senescence. A hypothesis is put forth to explain the toxicity of sugar accumulation, in relation to the role played by free radicals (Paulin, 1985).

Browning index as affected by 6-BAP and sucrose in the third day of storage is shown in Fig. 2. In the third day of storage, lowest browning was observed in flowers treated with 15 ppm 6-BAP without sucrose. Browning was highest in flowers treated with $20 \mathrm{ppm} 6-\mathrm{BAP}$ with $8 \%$ sucrose. At each 6-BAP level, browning was accelerated with gradual increase in sucrose concentration (Fig. 2). Fading index and percentage weight loss also showed a common trend in response to 6-BAP and sucrose. 


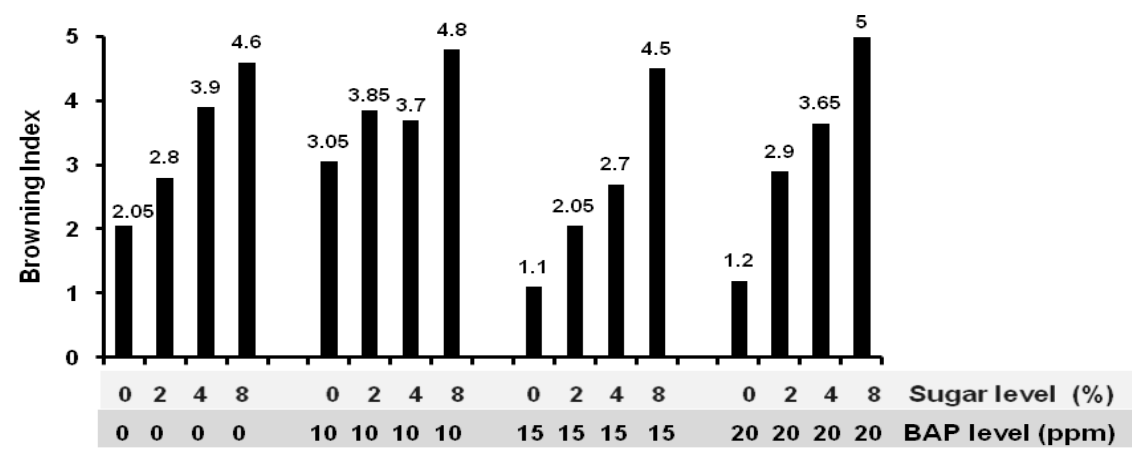

Treatment Combinations

Fig. 2. Browning index as affected by 6-BAP and sucrose in the $3^{\text {rd }}$ day of storage

In general, sacred lotus flowers have short vase-life of 2-3 days because they produce high ethylene. Most aquatic plants usually accumulate aminocyclopropane-1-carboxylic acid (ACC), an intermediate substance in ethylene production, as a prompt response to the environment during growth and development. Ethylene initiates premature senescence and probably encourages polyphenol oxidase to polymerize phenolic substances turning lotus petal colour to browning and dehydration (Suanphairoch et al., 2006). Application of 6-BAP delayed the petal senescence in cut carnation flowers (Cook et al., 1988).

The extent of flower opening as affected by 6-BAP and sucrose in the third day of storage is shown in Fig. 3.

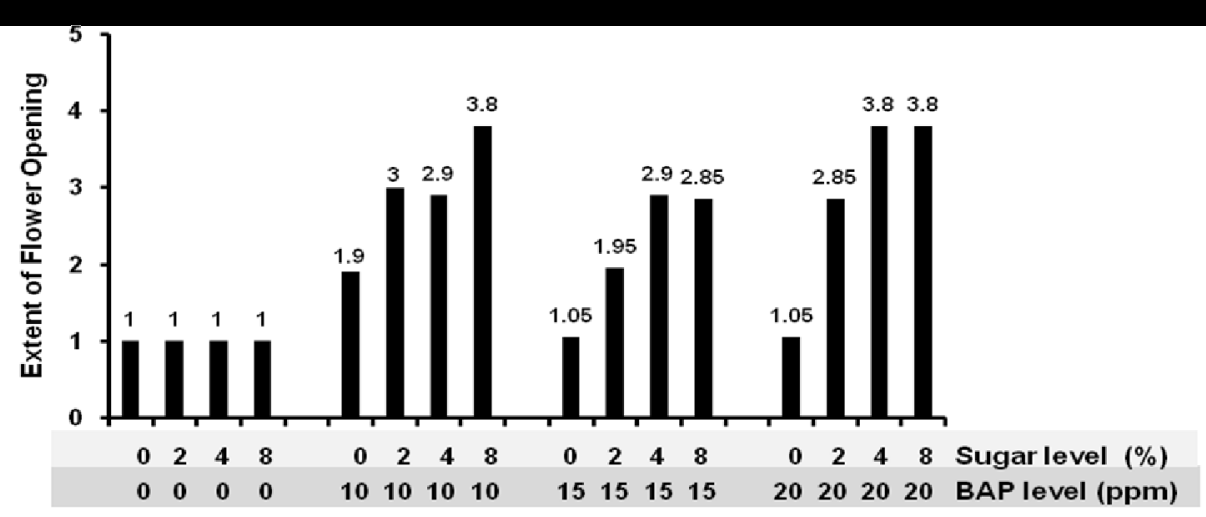

Treatment Combinations

Fig. 3. The extent of flower opening as affected by 6-BAP and sucrose in the $3^{\text {rd }}$ day of storage (completely closed flowers were considered 'good')

In the third day of storage, flower opening was lowest in the flowers treated without 6-BAP, whereas flower opening was comparatively lower in the flowers treated with 15 ppm and 20 ppm 6-BAP without sucrose. In the presence of 6-BAP, flower opening was accelerated with gradual increase in sucrose concentration (Fig. 3). According to the observations, lotus flower opening was enhanced by adding cytokinin (6-BAP) coupled with sucrose. 
During flower opening and growth high resources are needed. Cytokinins enhance the ability of young tissues to act as sinks for phloem transport. Cytokinins in reproductive structures might have a survival value by enhancing movement of sugars, amino acids, and other solutes from mature leaves into seeds, flowers, and fruits (Salisbury and Ross, 1991). A large amount of soluble carbohydrates is required for flower bud opening as substrates for cell walls and respiration as well as for their osmotic properties. Since the carbon source of cut flowers is limited, sugars such as sucrose and glucose added to vase water are highly effective in promoting flower opening. Sucrose at a concentration of $\geq 5 \mathrm{~g} / \mathrm{l}$ promoted bud opening in hybrid Limonium (Shimamura et al., 1997). But, in N. nucifera, flower opening accelerated further deterioration with significant increase in wilting and petal falling. Since, treatment with $15 \mathrm{ppm}$ 6-BAP without sucrose showed least effect in all parameters including lower petal falling, it could be identified as the best concentration for the holding solution.

Sucrose is the most common food source used in floral preservatives which is used at $2 \%$ standard amount (Gast, 1997). Pulsing or loading is a type of treatment used to extend the vase life of flowers held in water, stored wet or dry for long periods or shipped long distances. It is called a pulse because it is only done for a short period of time. Stems are placed in solutions with a germicide and a higher concentration of sugar for specific treatment periods depending on the species. Because the higher concentration of sugar can act like a soluble salt causing reverse osmosis resulting in petal and leaf injury, the treatment is only a few hours or a day (Gast, 1997). Therefore, possibility of pulsing flowers with $2 \%$ sucrose, (which was the lowest concentration used in the first experiment) for different time durations was tested in experiment two.

According to results of the second experiment, relatively low wilting, browning, fading, petal falling and $\%$ weight loss per day were observed when the flowers pulsed with $2 \%$ sucrose for $4 \mathrm{~h}$ compared to other treatments. According to Fig. 4, wilting index was lowest in the flowers pulsed with $2 \%$ sucrose for $4 \mathrm{~h}$ whereas highest wilting was observed in the control (flowers kept without pulsing).

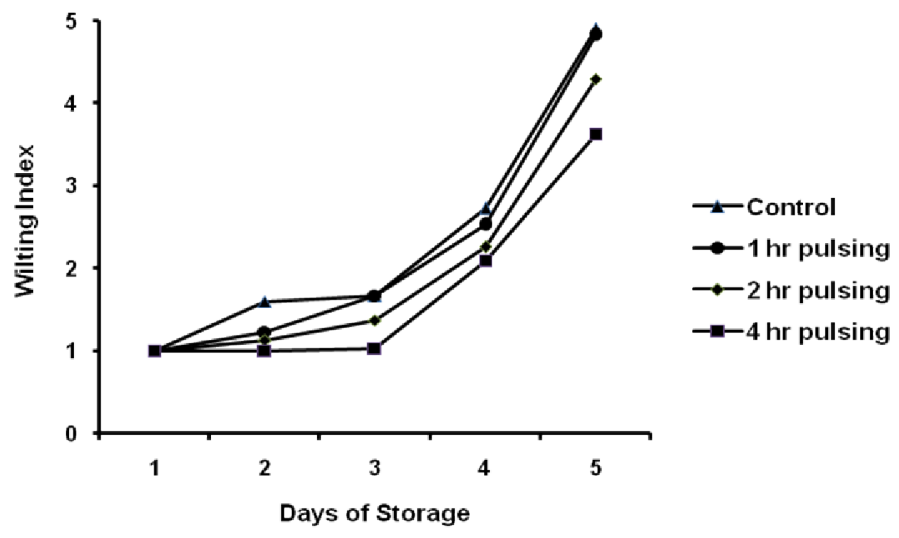

Fig. 4. Wilting index change over 5 days of storage period as affected by pulsing with $\mathbf{2 \%}$ sucrose for different time durations

There was a significant difference $(p<0.05)$ among treatments for wilting index, browning index and fading index over 5 days of storage period. But the treatment effect was nonsignificant $(p>0.05)$ for petal falling index and \% weight loss per day up to third day of 
storage (Fig. 5). Third day onwards there was a significant difference $(\mathrm{p}<0.05)$ among treatments for those indices.

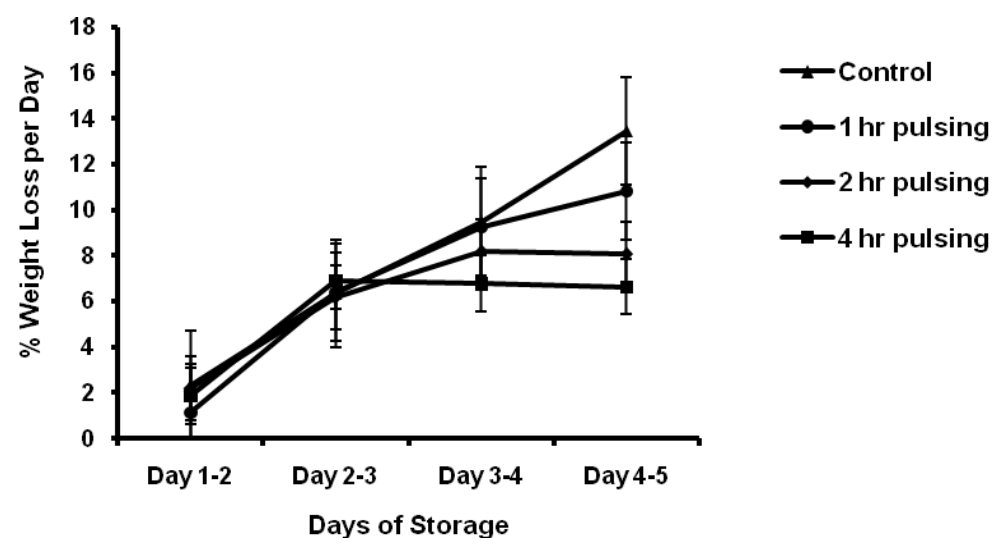

Fig. 5. Percentage weight loss per day over 5 days of storage period as affected by pulsing with $2 \%$ sucrose for different time durations

Eason et al. (1997) demonstrated that Sandersonia aurantiaca flowers on sucrose pulsed stems were larger, firmer and brighter orange than the control flowers; flowers that were treated with sucrose also contained greater quantities of carotenoids, soluble and storage carbohydrates and soluble proteins than the control flowers; the first visible signs of senescence occurred prior to any net loss of soluble carbohydrates or proteins. Pulsing with sugars is considered to accelerate water uptake in cut-flowers, the maintenance of carbohydrates may contribute to the maintenance of water uptake and retard wilting in the capitula in 'Seiun' flowers (Adachi et al., 2000). Browning index and fading index also behaved similar to the wilting index.

\section{CONCLUSIONS}

6-BAP 15 ppm alone was effective in maintaining flower quality. The effectiveness can be further increased by pulsing Lotus flowers initially with $2 \%$ sucrose for $4 \mathrm{~h}$ and subsequently placing them in 6-BAP $15 \mathrm{ppm}$ after pulsing, as the holding solution. Treated flowers in this way showed high quality up to 5 days under ambient conditions. Lotus flower opening was enhanced when sucrose is coupled with 6-BAP.

\section{REFERENCES}

Adachi, M., Kawabata, S. and Sakiyama, R. (2000). Effects of temperature and stem length on changes in carbohydrate content in summer-grown cut chrysanthemums during development and senescence. Post-harvest Biol. and Technol. 20, 63-70.

Butt, S.J. (2005). Preservatives: Vase life of roses. Int. J. on Agric. Biol. 7 (1), 97-99. 
Cook, E.L., Van Staden, J. and Ackermann, C. (1988). Manipulating carnation petal senescence, I: The interaction and transport of benzyladenine and indoleacetic acid. Scientia Hort. 35 (1-2), 143-156.

Eason, J.R., Vrè, L.A.D., Somerfield, S.D. and Heyes, J.A. (1997). Physiological changes associated with Sandersonia aurantiaca flowers in response to sugar. Post-harvest Biol. and Technol. 12, 43-50.

Gast, K.L.B. (1997). Post-harvest handling of fresh cut-flowers and plant material. [online]. [Accessed on 20.03.2010]. Available at www.ksre.ksu.edu/library/hort2/mf2261.pdf

MINITAB 15.0 Statistical Software (2010). Software for quality improvement. [online]. [Accessed on 12.01.2010]. Available at http://www.minitab.com/en-US/default.aspx I

Mohan, R.H.Y. (1977). Prolongation of vase life of Lupinus hartwegii by chemical treatments. Scientia Hort. 7 (4), 377-382.

Patil, S.R. and Reddy, B.S. (2001). Effect of citric acid and sucrose on postharvest water relations, fresh weight and vase life of golden rod (Solidago canedensis L.). Karnataka J. of Agric. Sc. 14 (2), 427-430.

Paulin, A. (1985). Influence of exogenous sugars on the evolution of some senescence parameters of petals. Acta Hort. 181, 183-193.

Salisbury, F.B. and Ross, C.W. (1991). Plant physiology. $4^{\text {th }}$ Edition. Wadsworth Publishing Company, Belmont, California. pp. 383-393.

Shimamura, M., Ito, A., Suto, K., Okabayashi, H. and Ichimura, K. (1997). Effects of $\alpha$ aminoisobutric acid and sucrose on the vase life of hybrid Limonium. Post-harvest Biol. and Technol. 12, 247-253.

Suanphairoch, S., Plainsirichai, M., Pharphom, K. and Phu-ein-ooy, N. (2006). Role of ethylene on vase-life of sacred lotus flower (Nelumbo nucifera Gaertn). Agric. Sci. J. 37: 5 (Suppl.): 85-88. 